Sharif University of Technology
Scientia Iranica
SCIENTIA
I RAN I CA
http://scientiairanica.sharif.edu

Research Note

\title{
Application of petrographic image analysis for the assessment of chemical attack in the concrete segments of a tunnel
}

\author{
F. Moodi ${ }^{\mathrm{a}}$, A.A. Ramezanianpour ${ }^{\mathrm{a}}$, Q. Bagheri Chenar ${ }^{\mathrm{b}}$, and E. Riahi Dehkordi ${ }^{\mathrm{b}, *}$ \\ a. Concrete Technology and Durability Research Center (CTDRc), Department of Civil \& Environmental Engineering, Amirkabir \\ University of Technology, Tehran, Iran. \\ b. Department of Civil \& Environmental Engineering, Amirkabir University of Technology, Tehran, Iran.
}

Received 29 November 2016; received in revised form 6 January 2018; accepted 28 July 2018

\author{
KEYWORDS \\ Concrete durability; \\ Petrographic image; \\ Chemical attack; \\ Sulfate; \\ Crack.
}

\begin{abstract}
The current study discusses the petrographic image analysis performed on core specimens that are extracted from a tunnel in the south west of Iran. During tunnel excavation, damages were observed in the inner sections of concrete segments. Due to field observations of damaged segments, environmental parameters, and tunnel location, several damage scenarios were proposed. In order to assess damage mechanisms, 69 cores were extracted and a number of standard tests were carried out. Since chemical attacks alter microscopic properties of materials, petrographic image analysis was performed on five specimens to evaluate possible microscopic changes in concrete composition. The results show that petrographic image analysis is an efficient method to provide a profound insight into the effects of chemical attacks on concrete members.
\end{abstract}

(C) 2020 Sharif University of Technology. All rights reserved.

\section{Introduction}

An essential characteristic of concrete is its durability, which determines the service life span of concrete structures [1]. However, numerous factors threaten concrete durability. Among these parameters, acidic attack plays an important role due to the alkalinity of cement-based materials and increasing sources of the acidic environment resulting from human activities [1]. A common form of chemical attacks in acidic environments is sulfate attack. The interaction of sulfate ions and cement paste matrix results in the expansion and progressive loss of strength and mass $[2,3]$.

\footnotetext{
*. Corresponding author. Tel.: +982164543074 E-mail address: fmoodi@aut.ac.ir (F. Moodi); aaramce@aut.ac.ir (A.A. Ramezanianpour); qasembagheri@aut.ac.ir (Q.Bagheri Chenar); erfan.riahi@aut.ac.ir (E. Riahi Dehkordi)
}

doi: $10.24200 /$ sci. 2018.20792
Another phenomenon that affects concrete durability is Alkali-Silica Reaction (ASR). The ASR initiates when aggregates containing active $\mathrm{SiO}_{2}$ react with alkalis and form a hygroscopic and hydraulic gel. This gel will expand upon hydration and exert pressure that might lead to concrete damage and reduced durability [4-6].

Petrographic examinations were first used by geologists to identify rocks based on their mineral composition. In the early 20th century, photographic techniques were used in construction materials to evaluate their components and deterioration mechanisms [7]. Petrographic image analysis is used in various applications such as the assessment of firedamaged concrete [8], determination of ASR in aggregates of concrete pavement [9], study of leaching of cement paste in concrete [10], verification of materials formation in a reaction [11], etc. Petrographic image analysis is widely used for evaluating aggregate alkali reactivity [12-14]. However, there are limited studies 
that have conducted petrographic examinations to assess other damage mechanisms such as sulfate attack, too $[15-17]$.

The tunnel, which is assessed in this paper, is located in the southwest of Iran. During tunnel excavation, concrete segments were severely damaged in some parts. Several damage scenarios were proposed to identify the source of the failure. Due to the high concentration of $\mathrm{H}_{2} \mathrm{~S}$ gas and liquefaction of surface layers of concrete segments, sulfate attack (in the forms of TSA and sulfuric acid attack) was suggested. Furthermore, the contractor was required to investigate the likelihood of harmful mechanisms such as ASR. Therefore, 69 core specimens were taken from tunnel segments and a variety of standard tests were performed. The location of the core specimens is schematically shown in Figure 1. As seen in Figure 1, three specimens are cored in every $500 \mathrm{~m}$ along the length of the tunnel. Five samples were also extracted from the damaged area of the tunnel roof.

Mechanical properties of concrete-based materials are shown in Table 1 . The compressive strengths of about $57 \%$ of specimens were found to be lower than the specified compressive strength (35 MPa). Density measurement results were also shown based

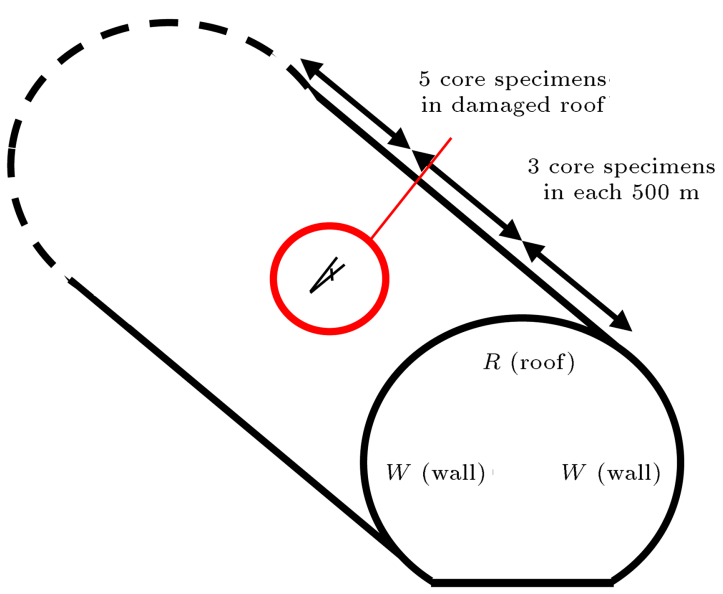

Figure 1. Schematic location of the specimens cored in the tunnel. on compressive strength. Concrete resistivity test results were more than $5 \mathrm{Kohm} . \mathrm{cm}$. Therefore, the probability of rebar corrosion in these specimens was low. On the other hand, bulk absorption results showed that the tunnel concrete was susceptible to an aggressive ions attack.

Along these tests, five specimens were selected, and the petrographic test was carried out similar to the RELIM AAR-1 method [18]. Although the main application of the RELIM AAR-1 method involves evaluating aggregate alkali-reactivity on the basis of its composition [19], as shown in this paper, it can be used to acquire additional information concerning possible chemical attacks that affect the microscopic structure of concrete.

\section{Material and method}

As stated in the previous section, the petrography technique used in this study is based on a similar procedure applied in the RELIM AAR-1 method. Five Specimens are studied in two phases. First, two transversal and four longitudinal sections are taken from each specimen. These sections are studied by the stereo microscope at $90 \times$ magnification to investigate the cement paste interaction with aggregates, voids, cracks, and so on (see Figures 2, 3, 5, 6, 8, 9, and 15). Suspicious sections are marked for further investigations. In the second phase, thin sections are prepared from the marked sections and studied thoroughly under a polarized microscope at $40 \times$ and $100 \times$ magnification to evaluate aggregates, cement paste changes, etc. (see Figures 4, 7, 10-14, and 16).

\section{Results and discussion}

The results of petrographic investigations are presented in in the following.

\subsection{Specimen 500R1}

Close observation shows a slight amount of white powder. This powder has been analyzed with X-Ray

Table 1. Mechanical properties of concrete-based materials.

\begin{tabular}{|c|c|c|c|c|}
\hline \multirow{3}{*}{$\begin{array}{c}\text { Compressive } \\
\text { strength (MPa) }\end{array}$} & \multicolumn{4}{|c|}{ Between 12 to 46} \\
\hline & $5 \%$ between & $26 \%$ between & $55 \%$ between & $14 \%$ between \\
\hline & 12 and 20 & 20 and 30 & 30 and 40 & 40 and 46 \\
\hline \multirow{3}{*}{$\begin{array}{c}\text { Density } \\
\left(\text { ton } / \mathbf{m}^{3}\right)\end{array}$} & \multirow{3}{*}{\multicolumn{2}{|c|}{$\begin{array}{c}\text { For compressive strength } \\
\text { between } 20 \text { and } 30 \mathrm{MPa} \\
2.220\end{array}$}} & \multirow{3}{*}{\multicolumn{2}{|c|}{$\begin{array}{c}\text { For compressive strength } \\
\text { more than } 30 \mathrm{MPa} \\
2.340\end{array}$}} \\
\hline & & & & \\
\hline & & & & \\
\hline $\begin{array}{l}\text { Resistivity } \\
\text { (Kohm.cm) }\end{array}$ & \multicolumn{4}{|c|}{ Between 16 and 55} \\
\hline \multirow{2}{*}{$\begin{array}{c}\text { Bulk } \\
\text { absorption }\end{array}$} & \multicolumn{4}{|c|}{ Between $3.2 \%$ and $7 \%$} \\
\hline & $50 \%$ betwee & $4 \%$ and $5 \%$ & $8 \%$ less than $4 \%$ & $100 \%$ more than $2 \%$ \\
\hline
\end{tabular}




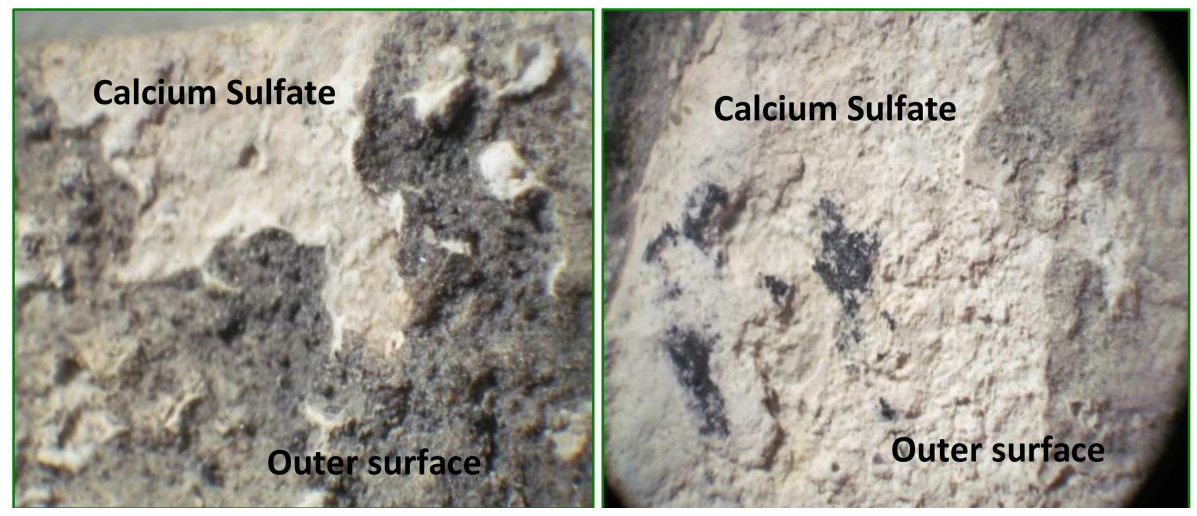

Figure 2. Specimen 500R1 transverse sections.

Table 2. Mineral content of the specimen 500R1 white powder.

\begin{tabular}{cccccc}
\hline Component & $\mathrm{So}_{4}$ & $\mathrm{CaO}$ & $\mathrm{MgO}$ & $\mathrm{Na}_{2} \mathrm{O}$ & $\mathrm{K}_{2} \mathrm{O}$ \\
\hline Ratio (\%) & 20.64 & 29.4 & 1.41 & 0.09 & 0.4 \\
\hline
\end{tabular}

Diffraction (XRD) method, and results are presented in Table 2. As shown in Table 2, the white powder contains calcium sulfate. Stereo microscopic study reveals small holes in the specimen's outer surface, filled up with the same calcium sulfate (Figure 2).

Two types of cracks are observed in the specimen. The first one is found on the surface of aggregates and is filled. These "primary cracks" are inherent in aggregates and are not related to tunnel construction. "Secondary cracks" start from aggregate cores and continue towards the margin of aggregates and voids. Secondary cracks are mainly due to alkali reactions and result in cement weakening (Figure 3 ).

Aggregates are calcareous. The observed aggregates are divided into two groups: stones and crystals. To be specific, $60 \%, 8 \%, 5 \%$ of stone aggregates are lime dolomites, dolomite stone, and chert, respectively. Around $10 \%$ of aggregates are crystals that consist mainly of calcite and a little gypsum. Dark rims encircle the majority of aggregates. Moreover, a number of white rims are visible at the boundary of aggregates and cement paste. These rims indicate a possible aggregate reaction mechanism, which in this case could be the ASR.

Thin section investigation verifies the presence of calcium sulfate accompanied by anhydrates. In addition, it is shown that chert minerals contain microcrystalline and kryptocrystaline silica, increasing ASR potential (Figure 4).

\subsection{Specimen 2500R1}

Close observations show ferrous oxide and calcium sulfate in layers that are close to tunnel segments. Stereo microscopic studies show that specimen transverse sections are entirely filled up with calcium sulfate. Aggregation dissolution traces are evident in these sections (Figure 5).

Aggregation composition is similar to specimen 500R. As shown in Figure 6, the same white and yellow rims are clearly seen.

Figure 7 shows a thin section study of specimen 2500R1. It reveals a yellow layer in the boundary of the majority of aggregates. Moreover, it shows voids filled with anhydrate crystals, indicating chemical attack. The adhesion of cement paste and aggregates
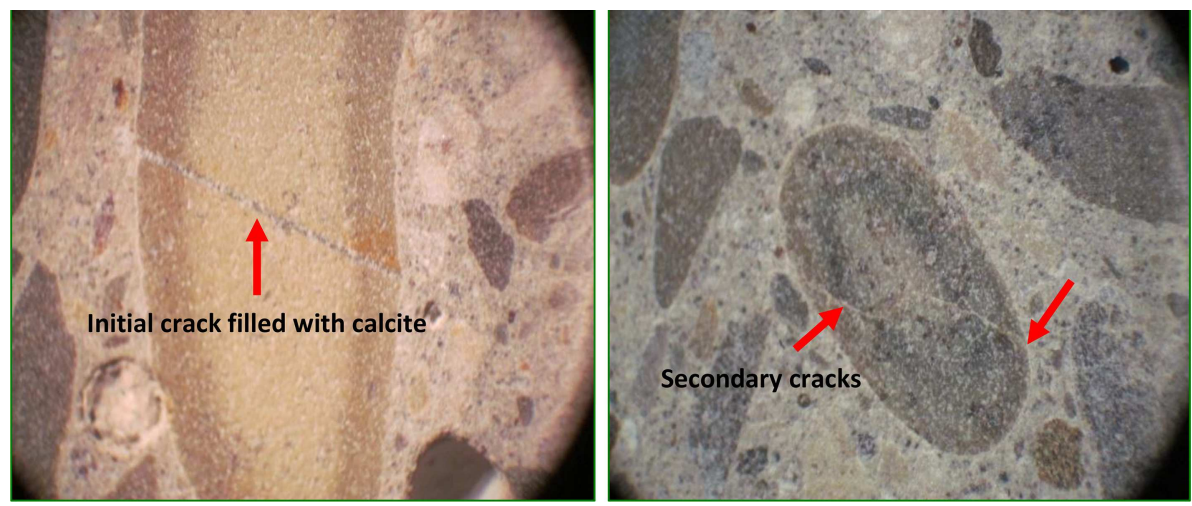

Figure 3. Secondary and primary cracks in specimen 500R1. 


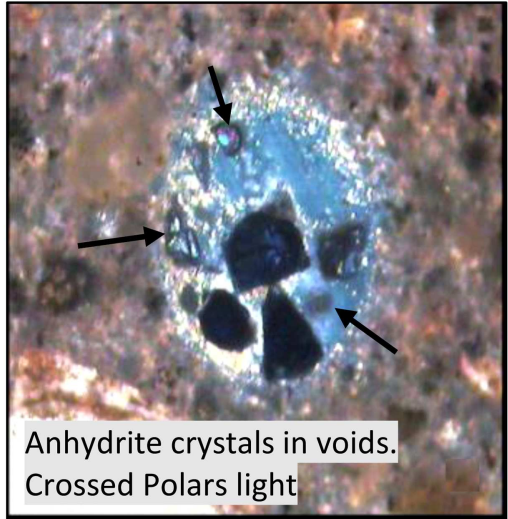

(a)

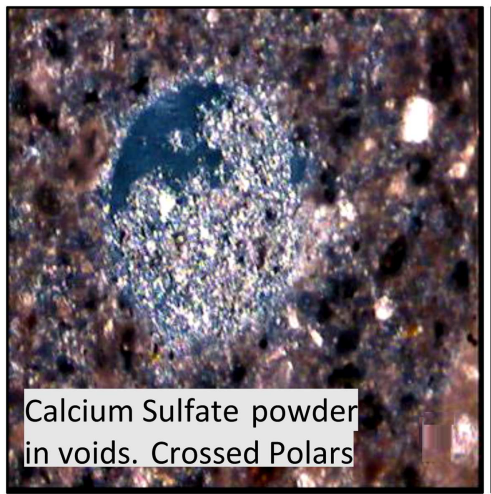

(c)

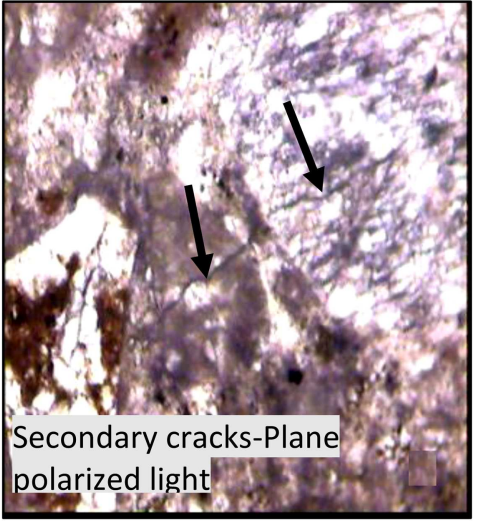

(b)

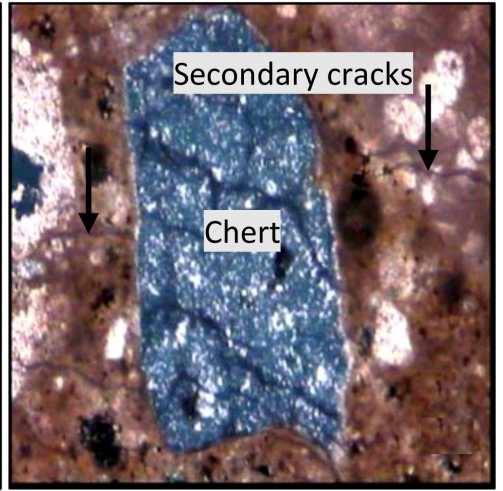

(d)

Figure 4. Thin section study of specimen 500R1: (a) Anhydrate, (b) secondary cracks, (c) calcium sulfate, and (d) chert.
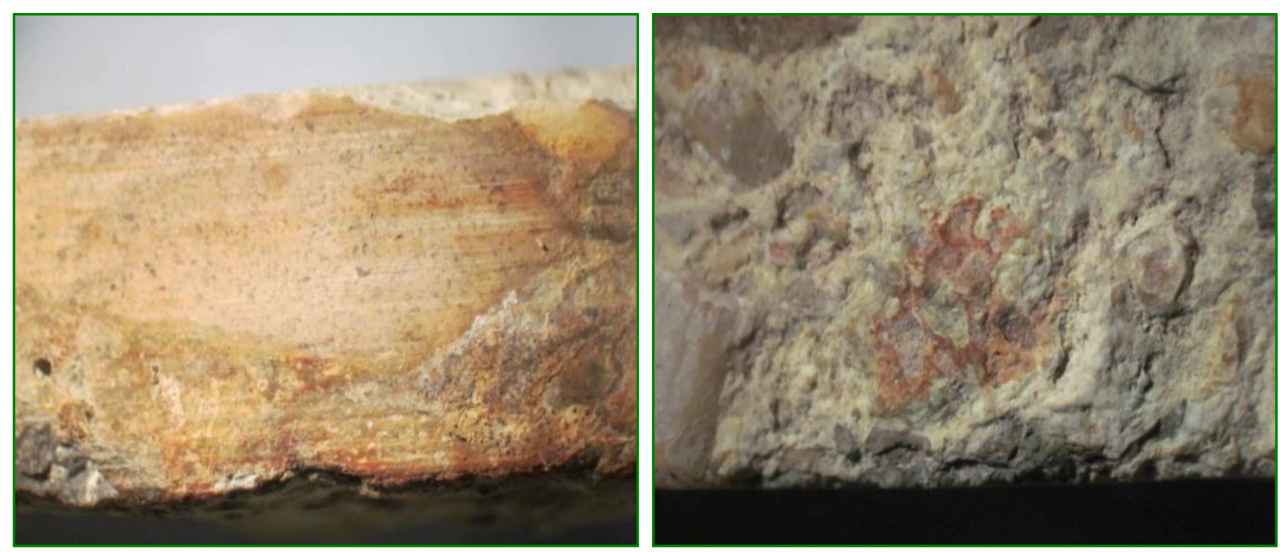

Figure 5. Specimen 2500R1 transverse sections.

is weakened and carbonation is apparent around some of the aggregates.

\subsection{Specimen 11500}

Again, the white powder containing calcium sulfate is observed in outer sections, which were exposed to tunnel environment. Ferrous oxide and corrosion are visible in aggregates. Therefore, the symptoms of a chemical attack are available in this specimen, too (Figure 8). As shown in Figure 9(a) and (b), reaction rims (dark rims) and white rims (between aggregates and cement paste) are seen. In some cases, ferrous oxide and aggregate segregation are visible. Close to the end of specimens, these signs are less visible.

Figure $9(\mathrm{c})$ and (d) show secondary and primary cracks that spread in the specimen. Ferrous oxide is observed along some cracks.

Polarize microscopic investigations show that anhydrate exists in some of the voids. Gypsum mineral presence, yellow layers, and dark rims are other signs 

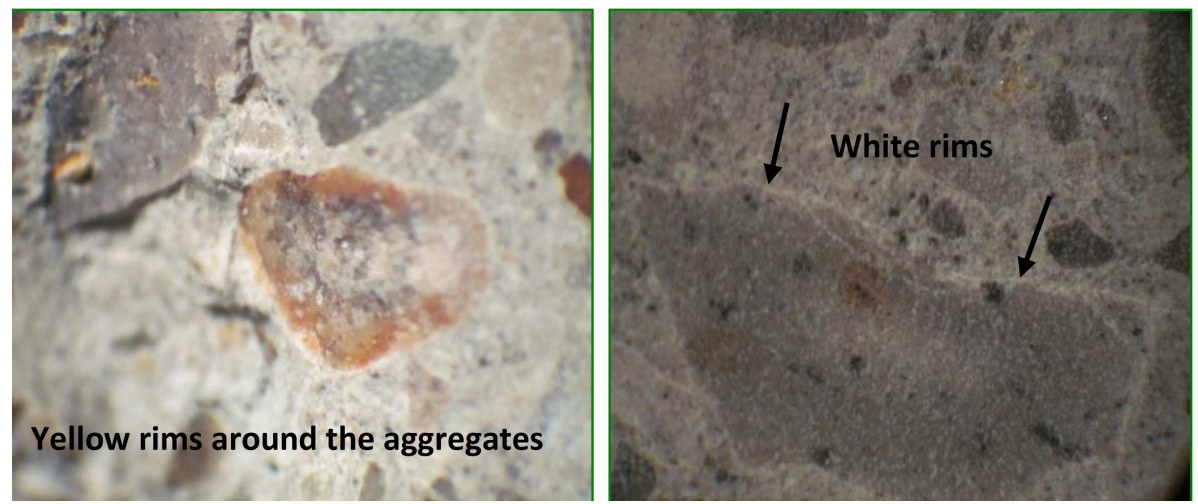

Figure 6. Specimen 2500R1 white and yellow rims.

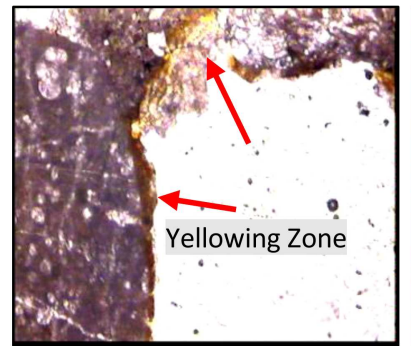

(a)

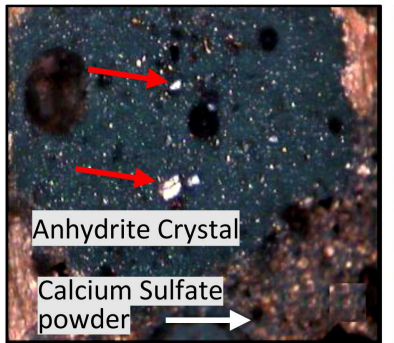

(b)

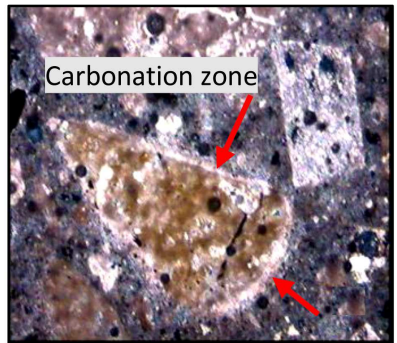

(c)

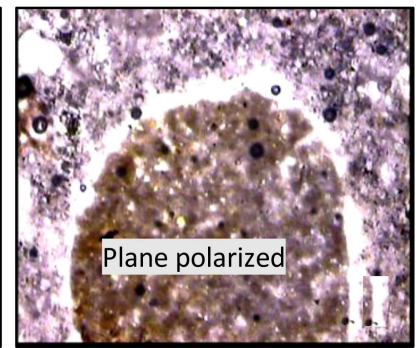

(d)

Figure 7. Specimen 2500R1 thin section study: (a) Yellow layer, (b) anhydrate, (c) and (d) carbonation.
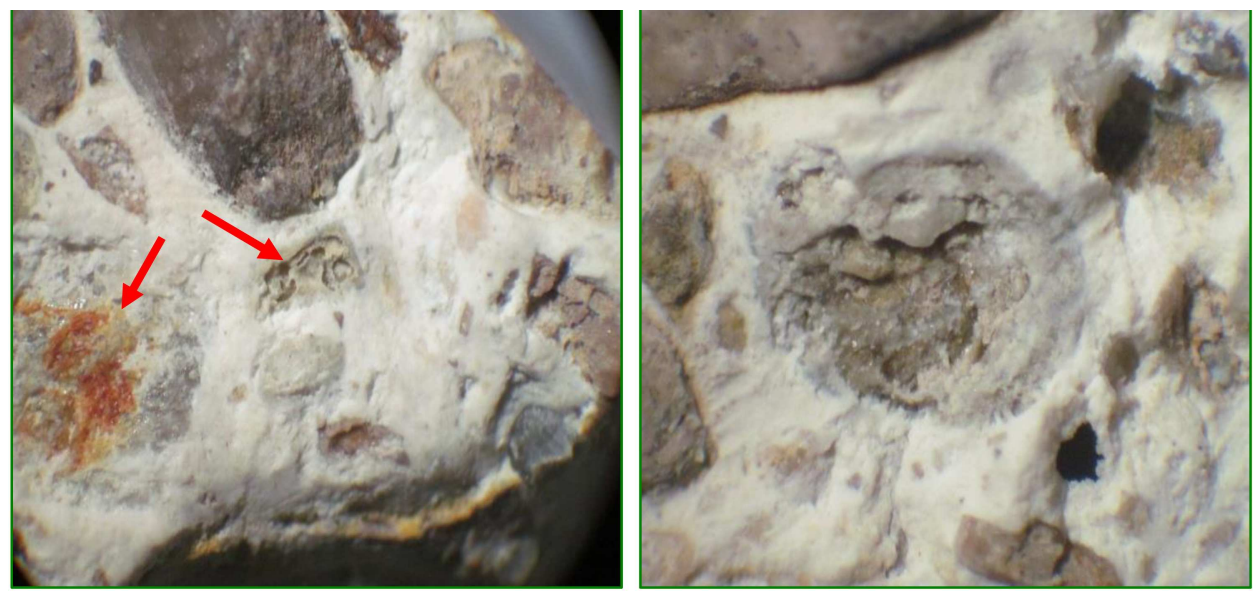

Figure 8. Specimen 11500R1 transverse sections.

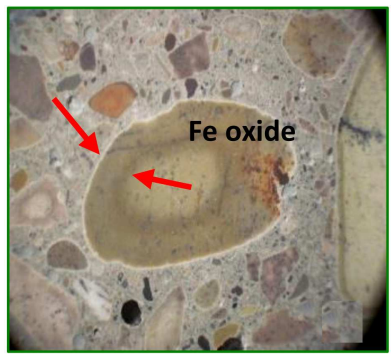

(a)

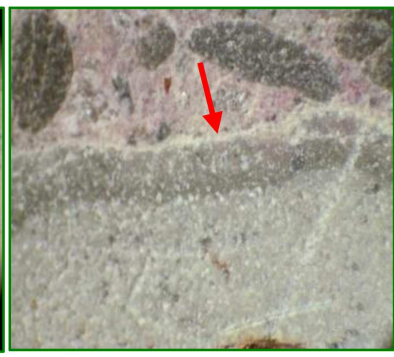

(b)

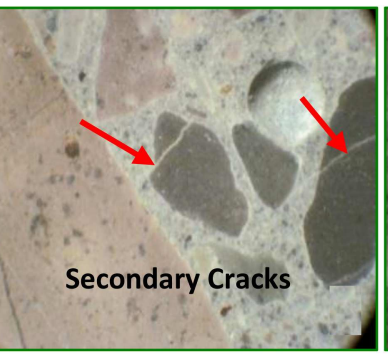

(c)

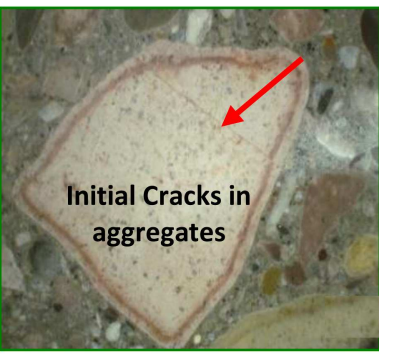

(d)

Figure 9. Specimen 11500R1 longitudinal section: (a) and (b) white and dark rims, (c) secondary, and (d) primary cracks in aggregates. 


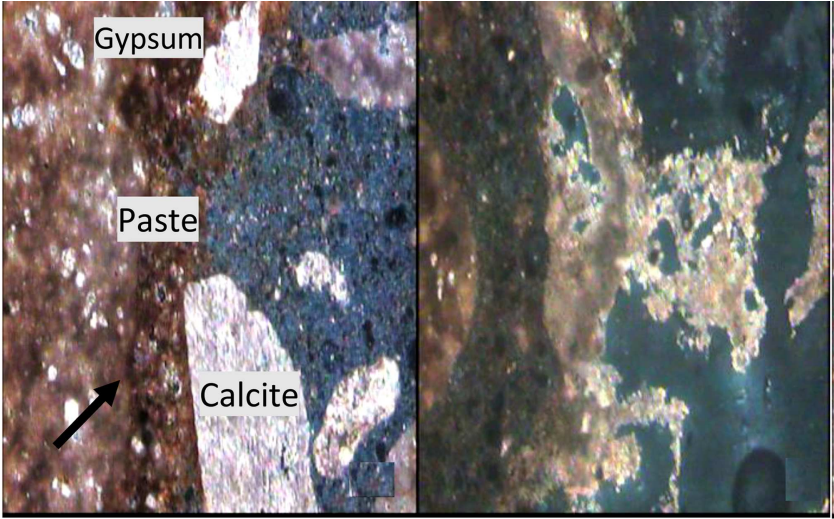

(a) (b)

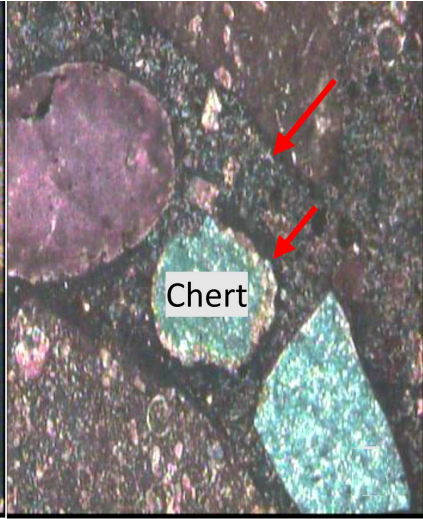

(c)

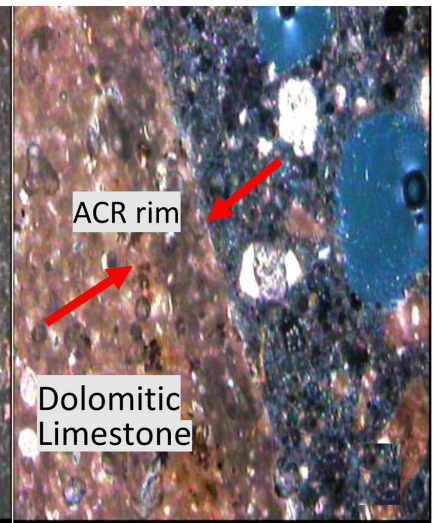

(d)

Figure 10. Specimen 11500R1 thin section: (a) and (b) outer surface, (c) and (d) inner surface.

of a possible acidic attack. Moreover, carbonation conditions are met in some part of the specimen. Figure 10(a) and (b) show the outer surface. Gypsum mineral and yellowish cement paste around the aggregates are clearly seen. Figure $9(\mathrm{c})$ and (d) are taken from the inner surface. Figure $9(\mathrm{c})$ shows the carbonation phenomenon as a dark layer around the aggregates. Figure $9(\mathrm{~d})$ shows reactivity rim as a dark rim around the dolomitic aggregate.

Figure 11 shows the yellowish texture that is seen around voids, aggregates, and cement paste matrix in areas that are attacked by invasive sulfate ions.

Aggregates consist of dolomitic limestone (40\%), siliceous limestone $(5 \%)$, dolomite $(10 \%)$, chert $(8 \%)$, and crystallines. Except for dolomite, the rest of these aggregates have high alkali-silica or carbonation potential. Weak aggregate-cement adhesion and acidic dissolution are observed, too. Calcium Carbonate surrounding some aggregates and, also, carbonation rims are clearly seen in Figure 12.

Voids' sizes are about $0.2 \mathrm{~mm}$ to $1.5 \mathrm{~mm}$. A large number of voids are spherical. Anhydrite crystals grew in some of the voids that support "sulfate attack" scenario. Carbonation occurs alongside these voids. Secondary cracks spread in this specimen, too (Figure 13).

\subsection{Specimen 12500L}

This specimen is not much affected by chemical attack. Slight corrosion and ferrous oxide are visible, but cement paste is strongly connected to aggregates. The aggregate composition is the same. Although secondary cracks are available, they did not grow more than a few millimeters. However, the polarized light microscopic investigation shows the evidence of an acidic attack in the form of yellowish layers and anhydrate minerals inside of the voids. Secondary cracks are available here, too (Figure 14).

\subsection{Specimen $14500 R$}

As shown in Figure 15, the burnt-colored aggregate in the first $2.5 \mathrm{~cm}$ of the specimen depth is a strong sign of acidic attack. Figure 16 shows white and dark rims and secondary cracks. Voids close to the tunnel segment surface are filled up with calcium sulfate and anhydrate.
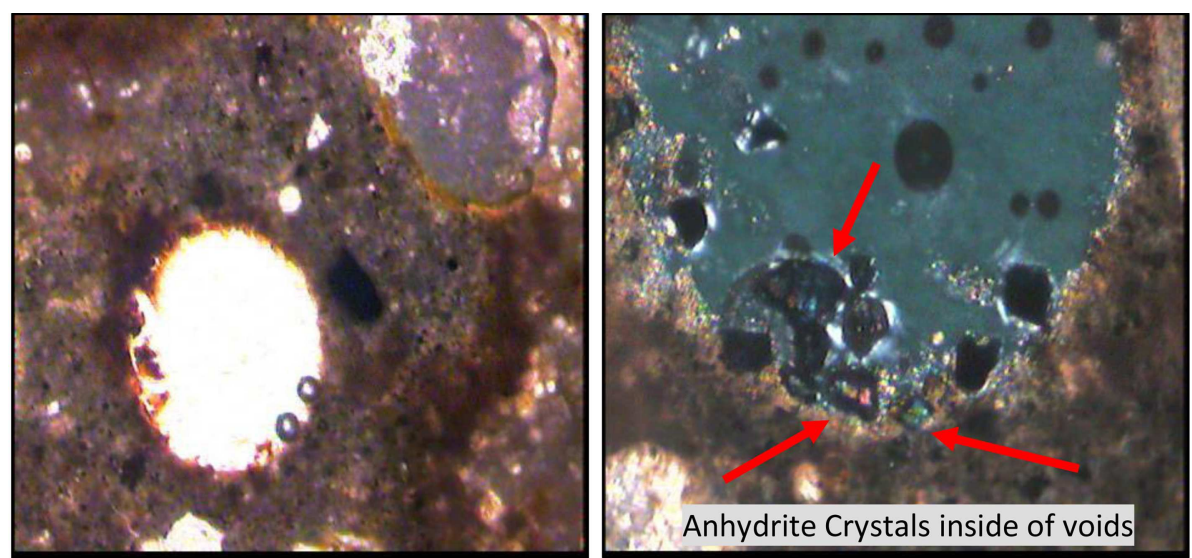

Figure 11. The yellow texture in specimen 11500R 1 thin sections. 

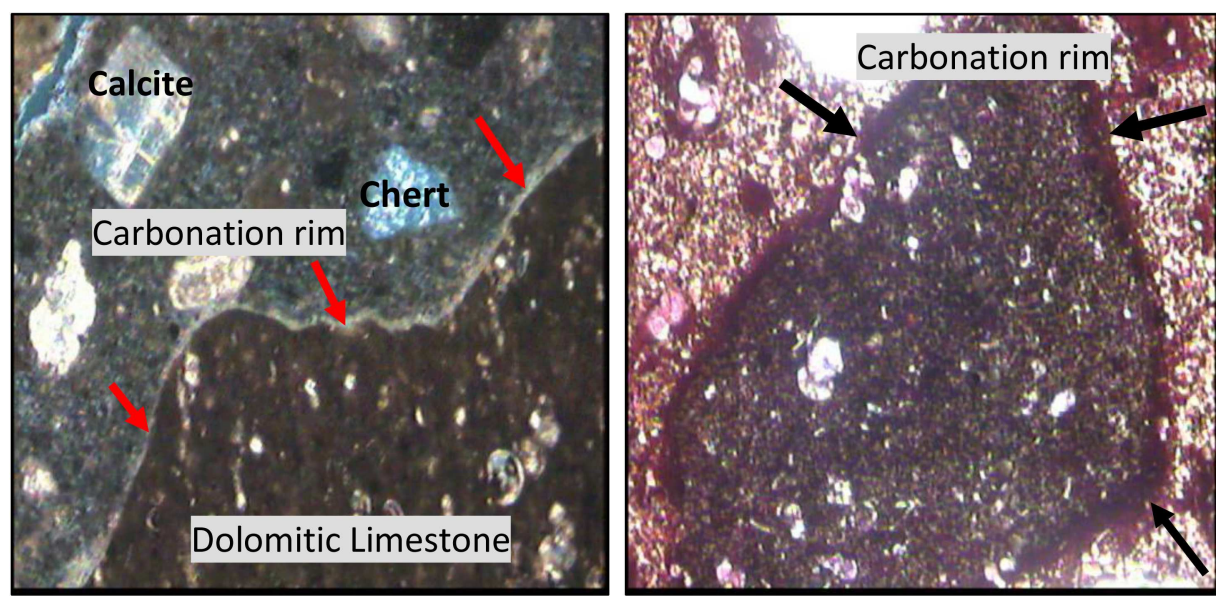

Figure 12. Carbonation rim visible in specimen 11500R1.

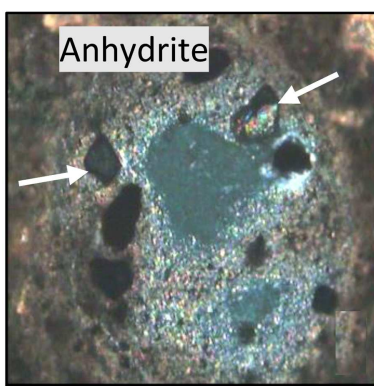

(a)

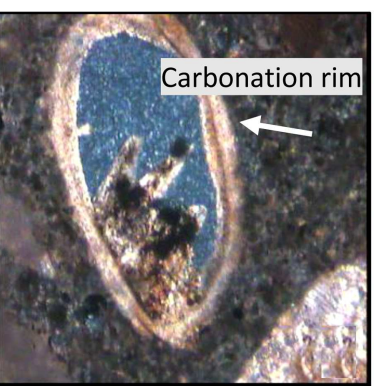

(b)

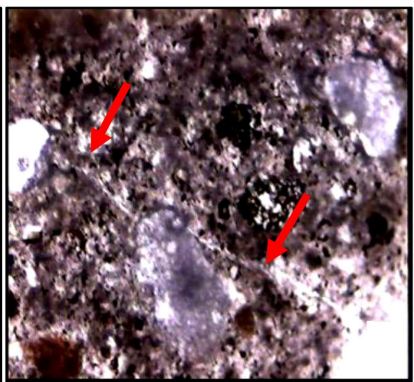

(c)

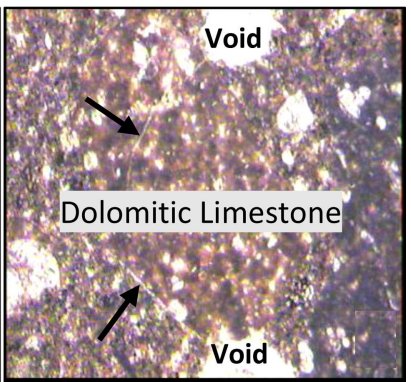

(d)

Figure 13. Specimen 11500R1 voids investigation: (a) Anhydrite, (b) carbonation rim, (c) and (d) primary and secondary cracks.

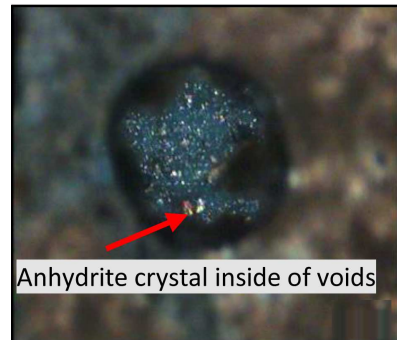

(a)

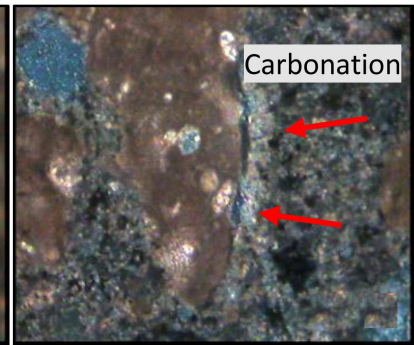

(b)

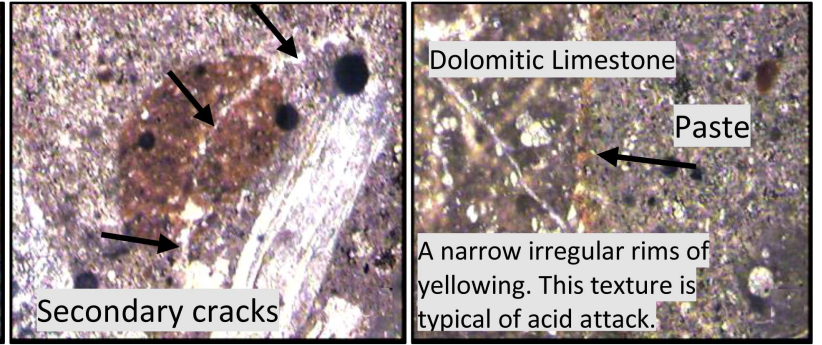

(c)

(d)

Figure 14. Specimen 12500L thin section study: (a) Anhydrite presence, (b) carbonation, (c) secondary cracks, and (d) yellowish layer.
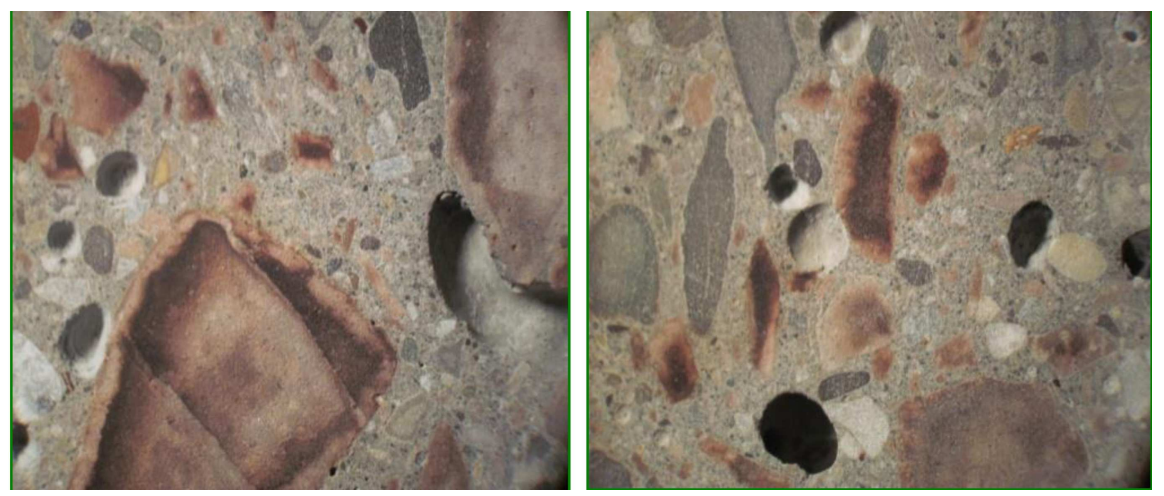

Figure 15. Burnt aggregates in specimen 14500R longitudinal sections. 


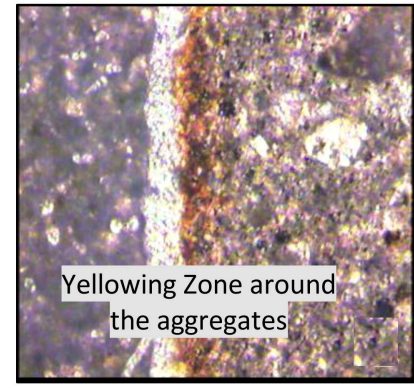

(a)

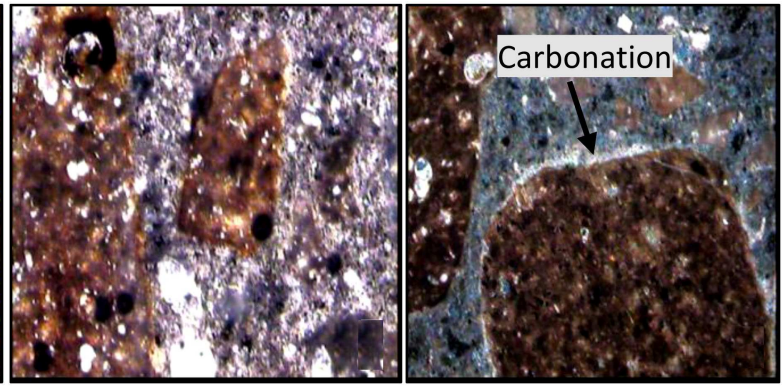

(b) (c)

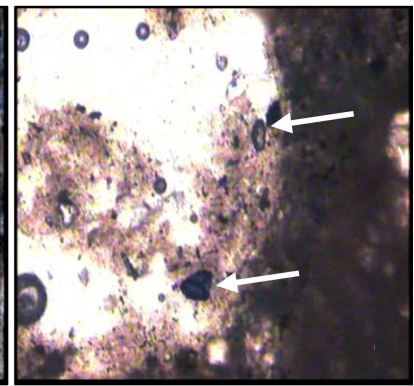

(d)

Figure 16. Specimen 14500R thin section: (a) Yellowish layer, (b) burnt aggregates, (c) carbonation, and (d) anhydrate and calcium sulfate in voids.

\section{Conclusion}

White powder containing Calcium Sulfate was observed in the specimens. Moreover, polarized microscopic studies showed the presence of anhydrate and calcium sulfate in specimens' voids. These minerals supported a sulfate attack mechanism. Burnt aggregates in specimen 14500, yellowish layer detected in specimens, dissolved aggregates and oxidation indicated that a sulfuric acid attack was likely. The mineralogy studies showed that most of the aggregates had high alkalisilica reactivity potential. Moreover, dark reaction rims encircled about $30 \%$ of aggregates, which supported Alkali-Silica Reaction (ASR) mechanism. White rims surrounding some aggregates and calcium carbonate existence represented a carbonation mechanism. Secondary cracks available in the specimens displayed aggregates alkali reactivity potential, too. Adhesion of cement paste to aggregates is usually strong except in widely attacked specimens. Secondary cracks due to alkali reactions resulted in aggregate segregation from the cement matrix, which intensified the current condition. The results show that the petrographic technique can provide additional information besides a typical ASR evaluation in chemical attack assessment. Therefore, petrography image analysis, combined with other standard tests, provides a thorough understanding of member failure sources and mechanisms due to aggressive chemical agents.

\section{References}

1. Ivica-ladim, R. and Adolf, A.A. "Acidic attack of cement ased materials- a review. Part 1: Principle of acidic attack", Construction and Building Materials, 15(8), pp. 331-340 (2001).

2. Ghafoori, N., Diawara, H., and Beasley, S.H. "Resistance to external sodium sulfate attack for earlyopening-to-traffic Portland cement concrete", Cement and Concrete Composites, 30(5), pp. 444-454 (2008).

3. El-Hachem, R., Rozière, E., Grondin, F., and Loukili, A. "New procedure to investigate external sulphate at- tack on cementitious materials", Cement and Concrete Composites, 34(3), pp. 357-364 (2012).

4. Nélia, C., Bjørn, E., Sorensen, M., and Broekmans, A.T.M. "Quantitative assessment of alkali-reactive aggregate mineral content through XRD using polished sections as a supplementary tool to RILEM AAR-1 (petrographic method)", Cement and Concrete Research, 42(11), pp. 1428-1437 (2012).

5. Chatterji, S., Thaulow, N., and Jensen, A.D. "Studies of alkali-silica reaction. Part 5: Verification of a newly proposed reaction mechanism", Cement and Concrete Research, 19(2) pp. 177-183 (1989).

6. Lukschová, Š., Přikryl, R., and Pertold, Z. "Petrographic identification of alkali-silica reactive aggregates in concrete from 20th century bridges", Construction and Building Materials, 23(2), pp. 734-741 (2009).

7. Fernandes, I. "Composition of alkali-silica reaction products at different locations within concrete structures", Materials Characterization, 60(7), pp. 655-668 (2009).

8. Ingham, P.J. "Application of petrographic examination techniques to the assessment of fire-damaged concrete and masonry structures", Materials Characterization, 60(7), pp. 700-709 (2009).

9. Št'astná, A., Šachlová, Š., Pertold, Z., Přikryl, R., and Leichmann, J. "Cathodoluminescence microscopy and petrographic image analysis of aggregates in concrete pavements affected by alkali-silica reaction", Materials Characterization, 65, pp. 115-125 (2012).

10. Larsen, G. "Petrographic method used in the study of leaching of cement paste in concrete", Engineering Geology, 1(3), pp. 189-199 (1966).

11. Sutter, L., Peterson, K., Touton, S., VanDam, T. and Johnston, D. "Petrographic evidence of calcium oxychloride formation in mortars exposed to magnesium chloride solution", Cement and Concrete Research, 36(8), pp. 1533-1541 (2006).

12. Marfil, S.A. and Maiza, P.J. "Deteriorated pavements due to the alkali-silica reaction: A petrographic study of three cases in Argentina", Cement and Concrete Research, 31(7), pp. 1017-1021 (2001). 
13. Patrice, R., Fournier, B., and Ballivy, G. "Quantitative petrographic technique for concrete damage due to ASR: experimental and application", Cement, Concrete and Aggregates, 22(1), pp. 63-72 (2000).

14. Rivard, P., Fournier, B., and Ballivy, G. "The damage rating index method for ASR affected concrete: a critical review of petrographic features of deterioration and evaluation criteria", Cement, Concrete and Aggregates, 24(2), pp. 81-91 (2002)

15. Ramyar, K. and Inan, G. "Sodium sulfate attack on plain and blended cements", Building and Environment, 42(3), pp. 1368-1372 (2007).

16. Sadananda, S. and Thaulow, N. "Delayed ettringite formation in Swedish concrete railroad ties", Cement and Concrete Research, 34(9), pp. 1675-1681 (2004).

17. Eden, M.A. "The laboratory investigation of concrete affected by TSA in the UK", Cement and Concrete Composites, 25(8), pp. 847-850 (2003).

18. Sims, I. and Nixon, P. "RILEM recommended test method AAR-1: detection of potential alkali-reactivity of aggregates-petrographic method", Materials and Structures, 36(7), pp. 480-496 (2003).

19. Lindgård, J., Nixon, P.J., Borchers, I., Schouenborg, B., Wigum, B.J., Haugen, M., and Åkesson, U. "The EU "PARTNER" project-European standard tests to prevent alkali reactions in aggregates: final results and recommendations", Cement and Concrete Research, 40(4), pp. 611-635 (2010).

\section{Biographies}

Faramarz Moodi, PhD, is an Assistant Professor in Construction Management at the Department of Civil and Environmental Engineering, Amirkabir University of Technology, Tehran, Iran. He received a BS degree in Civil Engineering, MS degree in Structural Engineering from University of Tarbiat Modares, Tehran, Iran in 1985 and 1989, respectively, and a $\mathrm{PhD}$ degree in Construction Management from University of Newcastle upon Tyne, Newcastle, UK in 2001. His research interests include concrete technology and durability, construction materials and evaluation of concrete structures.

Ali Akbar Ramezanianpour, $\mathrm{PhD}$, is a Professor in Concrete Technology at the Department of Civil \& Environmental Engineering, Amirkabir University of Technology, Tehran, Iran. He received BS and MS degrees in Civil Engineering from University of Tehran, Tehran, Iran in 1973 and 1975, respectively. He obtained a PhD degree in Material from University of Leeds, Leeds, England in 1987. His research interests include concrete technology, durability of concrete, repair of concrete structures, diagnosis of concrete structures, maintenance systems for concrete structures, Bridge Management System (BMS), Special concretes, concrete for dams, mix design and thermal analysis of roller compacted dams, durability of concrete in severe environments, pozzolanic cements, application of waste materials in concrete, high performance concrete, modeling of concrete durability, shrinkage, and creep of HPC concretes.

Ghasem Bagheri Chenar received MS at the Department of Civil \& Environmental Engineering, Amirkabir University of Technology, Tehran, Iran, where he also received his BS degree in Civil Engineering and MS degree in Construction Engineering and Management in 2013 and 2015 respectively. His research interests include: durability of concrete structures and also contract management.

Erfan Riahi Dehkordi Erfan Riahi Dehkordi is a PhD candidate at the Department of Civil \& Environmental Engineering, Amirkabir University of Technology, Tehran, Iran, where he also received his BS degree in Civil Engineering and MS degree in Construction Engineering and Management in 2014 and 2016, respectively. His research interests include durability of concrete structures and also project management. 